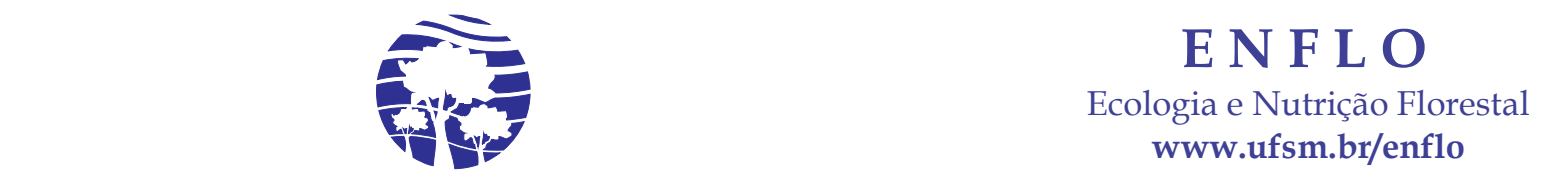

\title{
Análise das tendências nas relações entre fluxo de veículos, arborização e os níveis de intensidade de ruído ${ }^{1}$
}

\author{
Michelle Lara Porto²; Edmir dos Santos Jesus ${ }^{3}$; Antonio Pereira Junior ${ }^{4}$
}

\begin{abstract}
Resumo: A intensidade do ruído nos centros urbanos está diretamente ligada ao crescimento desordenado das cidades. Essa pesquisa objetivou analisar e relacionar os níveis de intensidade sonora provenientes do tráfego de veículos com a temperatura, velocidade do vento, fluxo de veículos e presença de vegetação na Praça da Bíblia, Bairro Cidade Nova, Marabá -PA, margem direita da Rodovia Transamazônica (BR 230). A metodologia empregada foi a exploratória, observativa, sistemática e direta. A área de estudo foi dividida em três seções: A e B, vias arteriais separadas por canteiro central contendo palmeiras, e C, via local, arborizada. Nas três seções, os dados foram coletados durante sessenta dias (abril-maio, 2016) em três horários (06h30min às 07h30min; 12h30min às 13h30min; 18h30min às 19h30min) em cinco pontos (P1, P2, P3, P4 e P5) distantes entre si em quarenta e cinco metros. Os dados obtidos indicaram, quanto à relação entre o fluxo de veículos e a intensidade do ruído, uma tendência a elevação da segunda variável, na seção C $(r=0,72)$; em relação as áreas arbóreas (altura total), os dados indicaram que a seção $C$, apresentou tendência a elevada intensidade de ruído $(r=0,72)$; quanto em função da altura total, houve tendência a diminuição $(r=0,72)$, mas, para o diâmetro, houve uma tendência de nulidade $(r=0,02)$, ou seja, essa variável não interfere na intensidade do ruído. Logo, a relação quanto à diminuição da intensidade do ruído, está relacionada com a altura da árvore, pois quanto mais baixa maior será a barreira sonora.
\end{abstract}

Palavras-chave: Subsistemas Urbanos; Plano de Arborização; Variáveis Ambientais.

\section{Analysis of trends in the relationships between vehicle flow, afforestation, and noise intensity levels}

\begin{abstract}
The intensity of noise in urban centers is directly linked to the disorderly growth of cities. The objective of this research was to analyze and correlate the noise intensity levels of vehicle traffic with temperature, wind speed, vehicle flow and presence of vegetation in Bible Square. Neighborhood Cidade Nova, Maraba -PA, right bank of the Transamazônica Highway (BR 230). The methodology used was exploratory, observational, systematic, and direct. The study area was divided into three sections: A and B, separated by a central bed containing palm trees, and C, woody. In the three sections, the data were collected during sixty days (April- May 2016) in three schedules (06h30 to 07h30, $12 \mathrm{~h} 30$ to $13 \mathrm{~h} 30,18 \mathrm{~h} 30$ to 19h30) in five points (P1, P2, P3, P4 and P5) distant between Si in forty-five meters. The data obtained indicated a tendency to increase the second variable, in the section $\mathrm{C}(\mathrm{r}=0.72)$, regarding the relationship between vehicle flow and noise intensity. In relation to tree areas (total height), data indicated that section $\mathrm{C}$ showed a tendency towards high noise intensity $(\mathrm{r}=0.72) ;(\mathrm{r}=0.72)$, but the diameter showed a tendency of nullity $(\mathrm{r}=0.02)$, that is, this variable does not interfere with the noise intensity. Therefore, the relation between the decrease in noise intensity is related to the height of the tree, because the lower the noise barrier.
\end{abstract}

Keywords: Urban subsystems; afforestation plan; environmental variables.

\footnotetext{
${ }^{1}$ Recebido em 19.06.2017 e aceito para publicação como artigo científico em 23.10.2017.

${ }^{2}$ Engenheira Ambiental; Departamento de Engenharia Ambiental, Universidade do Estado do Pará. E-mail: <michelle_lp@outlook.com>. 3 Meteorologista, Dr.; Professor substituto do Departamento de Engenharia Ambiental, Universidade do Estado do Pará. Email: <edmir.jesus@gmail.com>.

4 Biólogo, M.Sc; Professor do Departamento de Engenharia Ambiental, Universidade do Estado do Pará. Email: <jrecobio@yahoo.com.br>.
} 


\section{Introdução}

Nos centros urbanos a qualidade ambiental e o crescimento vivem em intensa concorrência, pois, na maioria das vezes, as cidades não comtemplam a qualidade ambiental em seus planejamentos. Nesse cenário, os cidadãos usufruem de toda a praticidade e conforto que a tecnologia oferece, mas, ao mesmo tempo, veem o ambiente ser deteriorado devido à poluição, ruído e falta de cobertura vegetal no espaço urbano (BUCHERRI FILHO e TONETTI, 2011).

Nesse contexto, a poluição sonora está diretamente ligada ao crescimento desordenado das cidades. Esse problema foi ampliado a partir da Revolução Industrial (1760) e, depois, na metade do século XX, com o inchaço dos centros urbanos e os elevados níveis de ruídos que levaram à criação das primeiras normas estipulando níveis permissíveis de emissões de ruídos (MURGEL, 2007). Ademais, as cidades costumam ter forte dinâmica econômica e os pontos de emissão de ruído são incontáveis, dentre os principais temos: o comércio, a indústria, obras de construção civil e o trânsito de veículos automotores, esses, têm elevado o nível de ruído urbano contribuindo para o surgimento de ambientes sonoros cada vez mais desagradáveis (LIMA e CARVALHO, 2010).

Umas das formas para impedir a propagação de grande parte da poluição sonora é a utilização da vegetação como barreira acústica, que pode reter o ruído de forma natural. Entretanto, a efetividade da barreira depende de diversos fatores, como: altura, comprimento e espessura da barreira, esses em relação à distância da fonte do ruído (NICODEMO e PRIMAVESI, 2009).

Decerto, a arborização atua no isolamento acústico porque as árvores em geral podem ajudar na diminuição dos ruídos, isso se realiza por cinco maneiras diferentes: na absorção do som, (elimina-se o som), pelo desvio da onda sonora (altera-se a direção do som), pela reflexão (o som refletido volta a fonte de origem), e pela refração, em que as ondas sonoras mudam de direção contornando um obstáculo, cobrindo, então, o som indesejado com outro agradável.
Para que a vegetação urbana absorva a contaminação sonora de forma adequada é necessário a utilização de uma cobertura vegetal densa num eixo com diferentes desníveis (MASCARÓ e MASCARÓ, 2010).

Nesse contexto, estudos (FANG e LING, 2003; TYAGI et al., 2006), avaliaram a atenuação relativa de ruído compreendidos entre 1,5 e $9,5 \mathrm{~dB}$ (A) $/ 20 \mathrm{~m}$, e relacionaram a magnitude deste parâmetro com a altura, a densidade, a largura e o comprimento da cintura verde que, em Portugal, é denominado cinturão verde.

Em face desses argumentos e das funções de atenuação e ruído a partir da arborização urbana, a presente pesquisa exploratória reveste-se de grande importância e tem como objetivo mensurar a tendência nas relações entre o fluxo de veículos, arborização presente e os níveis de intensidade sonora na BR-230, Transamazônica, em três seções diferentes com a presença de vegetação arbórea, em Marabá, PA.

\section{Material e métodos}

O município de Marabá localiza-se na região Amazônica, a sudeste do Estado do Pará, à margem esquerda do rio Tocantins. Com uma altitude média de $125 \mathrm{~m}$ em relação ao nível médio do mar, o município possui uma área de $15.157,90 \mathrm{~km}^{2}$. A vegetação predominante é de floresta ombrófila aberta, floresta ombrófila densa e áreas antrópicas, possui clima equatorial, quente e úmido, com média anual de $26^{\circ} \mathrm{C}$. A cidade de Marabá está situada em uma área de baixa altitude na confluência de dois rios - o Itacaiunas e o Tocantins (RAIOL, 2010).

Com relação às formas de relevo do município, essas estão englobadas pela unidade morfoestrutural denominada de Depressão Periférica do Sul do Pará, onde dominam os planaltos amazônicos rebaixados e dissecados, e das áreas colinosas, com áreas montanhosas mais ao Sul. Quanto à população total da cidade de Marabá, essa está cotada, de acordo com dados do último Censo realizado em 2010 pelo Instituto Brasileiro de Geografia e Estatística 
(IBGE), em 233.699 mil pessoas (MARABÁ, 2013). Ainda, segundo estatísticas do IBGE, a cidade de Marabá apresenta a terceira maior frota de veículos do Estado, com 99.921 unidades, em 2015.

A área de estudo localiza-se no bairro Cidade Nova, à margem direita (sentido Itupiranga) da Rodovia Transamazônica (BR 230), onde se situam as seções A e B, e à margem esquerda da Avenida Transamazônica, onde está localizada a seção C. A BR 230 pode ser considerada, de acordo com o estudo pioneiro (ZMITROWICZ e DE ANGELIS NETO, 1997), como uma via arterial, em um subsistema urbano por ser controlada por semáforo, com acessibilidade às vias secundárias e locais, possibilitando o trânsito entre as regiões da cidade. Já, a Avenida Transamazônica pode ser considerada como via local, por ser caracterizada por intercessões em nível não semaforizadas, destinadas apenas a acesso local ou área restrita (CAETANO, 2013).

Já a Praça da Bíblia, onde encontra-se a arborização, situa-se entre as seções $\mathrm{B}$ e $\mathrm{C}$, nas extremidades, entre duas vias coletoras (responsável por coletar e distribuir o trânsito.) A área localiza-se próxima a uma das saídas da cidade, sentido Nordeste-Sudoeste, ligando Marabá a cidade de Itupiranga, estando próximo à saída que dá acesso aos núcleos da Marabá Pioneira e Nova Marabá, sentido SudoesteSudeste, e foi dividida em três seções (Figura 1).

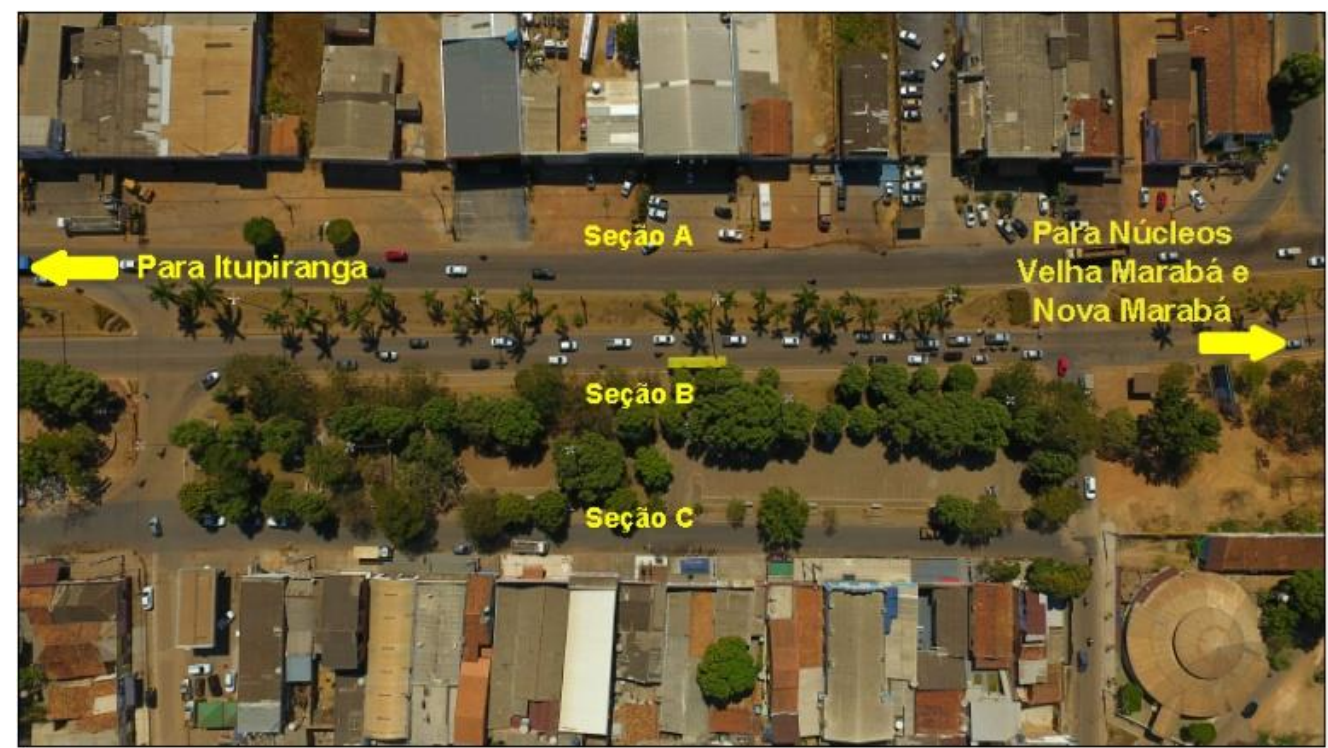

Figura 1 - Vista aérea da localização da área de estudo. Marabá - PA.

Figure 1 - Aerial view of the location of the study area. Maraba - PA.

Fonte: Autores (2016).

Cada seção, em linha reta, apresenta comprimento igual a $180 \mathrm{~m}$, e foi dividida em cinco pontos (P1, P2, P3, P4 e P5), distantes entre si, em $45 \mathrm{~m}$. Cada ponto em cada uma das seções fez-se a identificação das coordenadas geográficas (Tabela 1).

Quanto à análise da redução de níveis dos ruídos pela arborização, relacionou-se a altura total $(\mathrm{Ht})$ e o diâmetro médio da copa (DC) das árvores com os níveis de ruído na Seção C, pois essa é a seção que recebe a influência da barreira vegetal presente na Praça da Bíblia. Para melhor análise, dividiu-se o espaço ocupado pelas árvores em quatro áreas, cada uma com área total igual a $1.035 \mathrm{~m}^{2}$, que se localizam entre os pontos 1 e 5 das seções B e C (Figura 2). 
Tabela 1 - Coordenadas geográficas (Sul - S; W - oeste) dos cinco pontos (P1, P2, P3 P4 e P5) amostrais nas seções A, B e C. BR 230. Marabá - PA.

Table 1 - Geographic coordinates (South - S; W - west) of the five points (P1, P2, P3, P4 and P5) sampled in sections A, B and C. BR 230. Marabá - PA.

\begin{tabular}{|c|c|c|c|c|c|c|}
\hline \multirow{3}{*}{$\mathbf{P}$} & \multicolumn{6}{|c|}{ SEÇÃO } \\
\hline & \multicolumn{2}{|c|}{$\mathbf{A}$} & \multicolumn{2}{|c|}{ B } & \multicolumn{2}{|c|}{$\mathrm{C}$} \\
\hline & Latitude (S) & Longitude (W) & Latitude (S) & Longitude (W) & Latitude (S) & Longitude (W) \\
\hline P1 & $05^{\circ} 22^{\prime} 00^{\prime \prime}$ & $49^{\circ} 07^{\prime} 33.0^{\prime \prime}$ & $05^{\circ} 22^{\prime} 2.2^{\prime \prime}$ & $49^{\circ} 07^{\prime} 38.5^{\prime \prime}$ & $05^{\circ} 22^{\prime} 2.7^{\prime \prime}$ & $49^{\circ} 07^{\prime} 38.2^{\prime \prime}$ \\
\hline P2 & $05^{\circ} 21^{\prime} 58.5^{\prime \prime}$ & $49^{\circ} 07^{\prime} 35.9^{\prime \prime}$ & $05^{\circ} 22^{\prime} 1.2^{\prime \prime}$ & $49^{\circ} 07^{\prime} 37.5^{\prime \prime}$ & $05^{\circ} 22^{\prime} 1.9^{\prime \prime}$ & $49^{\circ} 07^{\prime} 37.0 "$ \\
\hline P3 & $05^{\circ} 21^{\prime} 59.5^{\prime \prime}$ & $49^{\circ} 07^{\prime} 37.0 ”$ & $05^{\circ} 22^{\prime} 0.2^{\prime \prime}$ & $49^{\circ} 07^{\prime} 36.4 ”$ & $05^{\circ} 22^{\prime} 1.0^{\prime \prime}$ & $49^{\circ} 07^{\prime} 35.9^{\prime \prime}$ \\
\hline P4 & $05^{\circ} 22^{\prime} 0.3^{\prime \prime}$ & $49^{\circ} 07^{\prime} 38.1^{\prime \prime}$ & $05^{\circ} 21^{\prime} 9.3^{\prime \prime}$ & $49^{\circ} 07^{\prime} 35.3^{\prime \prime}$ & $05^{\circ} 22^{\prime} 0.0^{\prime \prime}$ & $49^{\circ} 07^{\prime} 34.8^{\prime \prime}$ \\
\hline P5 & $05^{\circ} 22^{\prime} 1.2^{\prime \prime}$ & $49^{\circ} 07^{\prime} 39.2^{\prime \prime}$ & $05^{\circ} 21^{\prime} 58.3^{\prime \prime}$ & $49^{\circ} 07^{\prime} 34.2^{\prime \prime}$ & $05^{\circ} 21^{\prime} 9.1^{\prime \prime}$ & $49^{\circ} 07^{\prime} 33.5^{\prime \prime}$ \\
\hline
\end{tabular}

Fonte: Autores (2016).

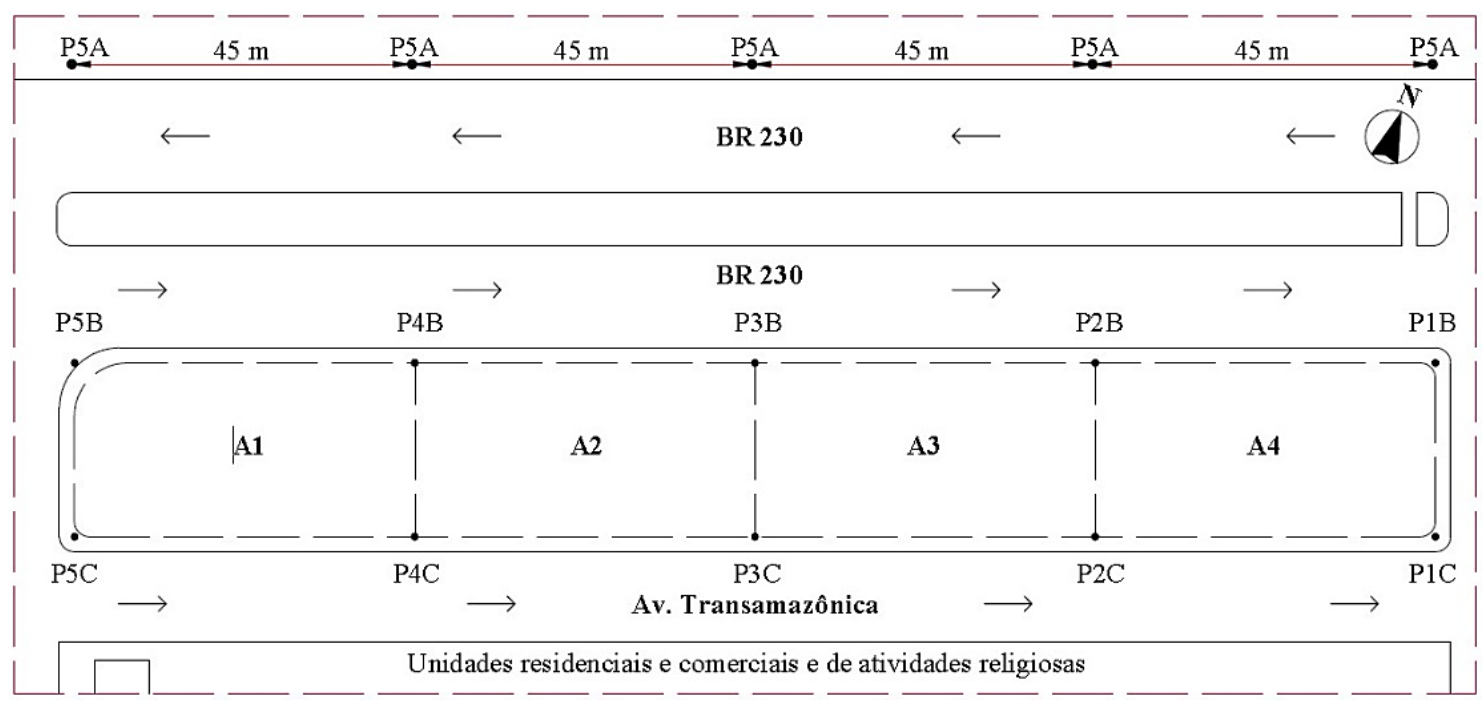

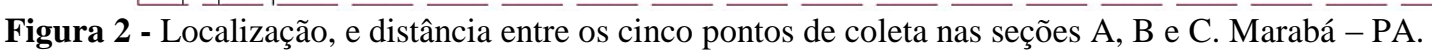

Figure 2 - Location, and distance between the five collection points in A, B and C sections. Maraba - PA.

Fonte: Autores (2016).

O espaço objeto dessa pesquisa pode ser considerado, como: "área mista com vocação comercial e administrativa", pois há predominância de prédios comerciais prestadores de serviços, bem como, a existência de edifícios de atividade religiosa (ABNT, 2000). A escolha da área de estudo ocorreu pela localização próxima da BR 230, que possui um fluxo muito grande de automóveis, pedestres e atividades que geram algum tipo de ruído (Ex.: oficinas de carro e moto). Além disso, uma das seções (C) encontra-se por detrás da barreira arbórea presente na praça.
Coleta de dados

As coletas dos dados para a realização do presente trabalho ocorreram do dia vinte de abril ao dia dezoito de junho do ano de 2016, as quais foram realizadas em 5 etapas:

(1) Levantamento de dados documentais, com recorte temporal compreendido entre 2007 a 2016.

(2) Mensuração e coleta das variáveis ambientais: ruído, altura total - Ht, e diâmetro da copa - DC, em horário único (08h00 min.), nas 
três seções (A, B e C), e cinco pontos distintos (P1, P2, P3, P4 e P5).

(3) Identificação e mensuração da altura total (Ht) dos vegetais lenhosos existentes nas seções B e C com o uso da Equação 1, a partir do método trigonométrico preconizado por Ribeiro (2011):

Onde:

$$
H t=\operatorname{tg} \theta \times D+H o
$$

$\mathrm{Ht}=$ altura total da árvore;

$\theta=$ ângulo visado, ou seja, a partir dos olhos do observador;

$\mathrm{D}=$ distância entre o observador a árvore (m);

Ho $=$ altura do observador (linha dos olhos).

Para o cálculo do diâmetro da copa, adaptouse a Equação 2, que foi proposta por Bertolini et al. (2012), pois as árvores existentes na Praça da Bíblia apresentam copas circulares.

$$
\mathrm{ACC} 4=Л(\mathrm{D} / 4)^{2}(2)
$$

Onde:

ACC4 = área da copa circular nos sentidos de cada ponto geográfico (Norte, Sul, Leste e Oeste);

$(\mathrm{D} / 4)^{2}=$ Diâmetro utilizado.

(4) Tratamento estatístico dos dados com o uso do software BioEstat 5.0 (AYRES et al., 2007), aplicação da estatística descritiva (média, desvio padrão, coeficiente de Correlação de Pearson).

(5) Captura da vista superior da área analisada com a aplicação de um Drone Dji, modelo Phanton 4.

Tratamento estatístico dos dados

Para o tratamento dos dados foram calculadas as médias dos valores de ruído, fluxo de veículos, altura total $(\mathrm{Ht})$ e diâmetro médio da copa (DC) das árvores. Para a realização dos testes de normalidade adotou-se o método de regressão linear, que consiste na realização de uma análise estatística para verificar a existência de uma relação funcional entre uma variável dependente com uma ou mais variáveis independentes (PETERNELLI, 2004). Também foi calculado o Coeficiente de Correlação de Pearson (r) que consiste na medida de associação linear de variáveis, ou seja, é a força da relação entre as variáveis, cujo coeficiente varia de $-1 \mathrm{a}+1$. Para esta pesquisa empregou-se os valores: $r=0$, não há correlação; 0,10 a 0,30 , correlação fraca; 0,40 a 0,60 , correlação moderada; 0,70 a 1,00 correlação forte (FIGUEIREDO FILHO e SILVA JÚNIOR, 2009).

Vale ressaltar que o presente estudo é de caráter exploratório e, portanto, não foram analisados os níveis de ruído da distância entre a fonte e o receptor, das unidades arquitetônicas, da velocidade média dos veículos, da rotação por minuto (rpm) dos motores dos veículos, do tipo de veículo (de som, de serviços de saúde, oficiais, etc.), do tráfego de transeuntes e nem foi calculada a velocidade de propagação da onda sonora, o que significa que a pesquisa foi realizada a fim de se comparar as tendências (aumento/diminuição) do ruído existente entre as seções e indicar se elas ocorreram ou não em função da arborização existente na Praça da Bíblia.

\section{Resultados e Discussão}

Relação entre fluxo veicular e intensidade do ruído

A análise dos dados obtidos quanto à relação entre o fluxo veicular e a intensidade do ruído nas seções pesquisadas (SA, $r=-0,43$; $\mathrm{SB}, r=-$ 0,$29 ; \mathrm{SC}, r=0,72$ ), indicou que houve uma tendência de relação moderada e fraca entre elas. Embora, tenha havido maior intensidade de fluxo veicular na seção B (25 veículos/minuto); na seção A (22 veículos/minuto); na seção C (2 veículos/minuto).

Tal análise indicou também que, apesar de haver uma intensidade de fluxo veicular intenso nas seções A e B, a tendência da intensidade sonora foi para similaridade $(50 \mathrm{~dB})$. A explicação e o paralelismo existentes entre essas seções, em que o fluxo veicular muda apenas de sentido, acarreta na interferência nos níveis de ruído da outra. Vale ressaltar que a similaridade entre os níveis de ruído nessas duas seções, 
podem estar associadas às características individuais de cada veículo (rpm do motor, velocidade média com a qual os veículos se deslocavam), do uso da buzina, do dispositivo de alarme sonoro (sirenes), do tráfego de veículos pesados, etc., que não foram objetos dessa pesquisa, e isso demonstra que, nem sempre os pontos em que transitava maior fluxo de veículos, apresentaram, necessariamente, o maior nível de ruído. Na seção $\mathrm{C}$, o fluxo de veículos, por minuto, foi igual a 2 .

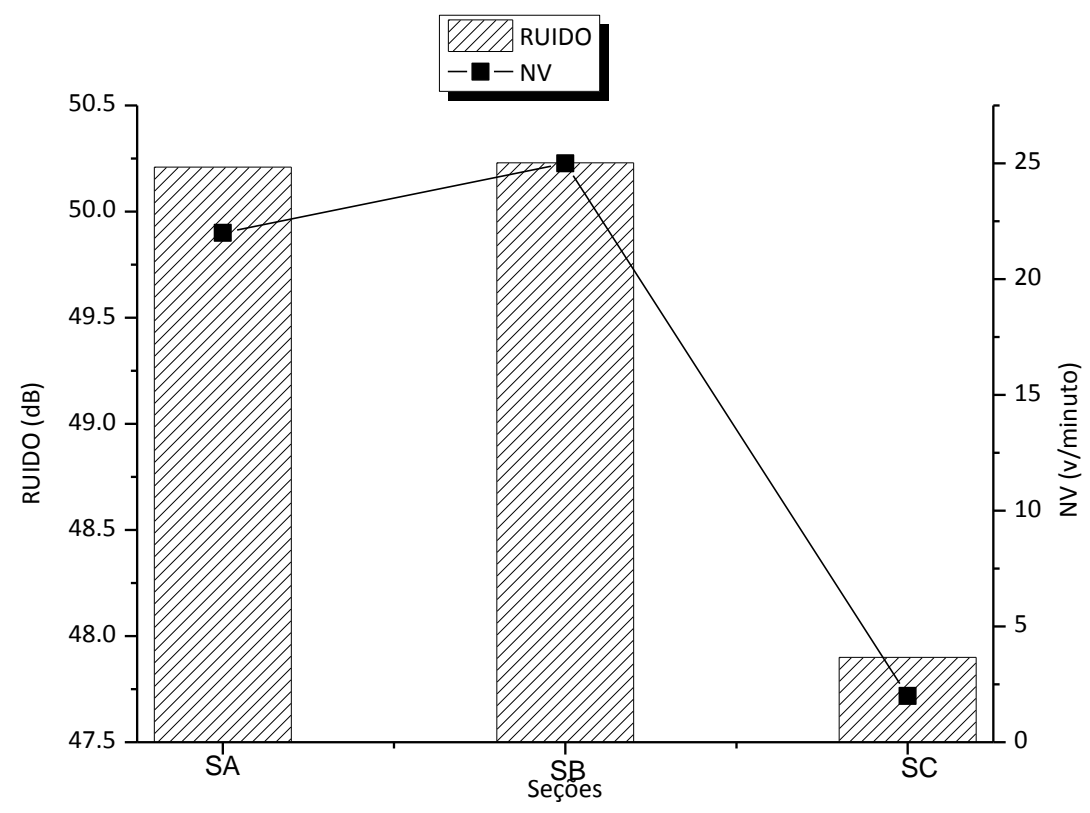

Figura 3 - Valores médios para o ruído e fluxo de veículos nas seções A, B e C. Marabá - PA.

Figure 3 - Mean values for noise and flow of vehicles in A, B and C sections. Maraba - PA.

Fonte: Autores (2016).

No estudo realizado na cidade de São Paulo SP, por Kawakita (2008), o autor concluiu que nem sempre, onde há maior número total de veículos, ocorre o maior valor do nível de ruído, pois, o fator que possui grande influência nos níveis de intensidade sonora é o tipo de veículo. $\mathrm{Na}$ pesquisa realizada em Marabá, não foi efetivado o estudo sobre o tipo de veículo e o ruído por ele emitido, mas, com relação ao fluxo de veículos, verificou-se que os resultados obtidos em Marabá, na seção C, da área pesquisada, são similares aos obtidos em São Paulo.

$\mathrm{Na}$ pesquisa, realizada em Natal $-\mathrm{RN}$, por Pinto et al. (2013), os dados obtidos e analisados indicaram que as vias arteriais (vias principais de subsistema urbano), são as mais movimentadas e, consequentemente, são as vias com maiores níveis de ruído. Como a localização das seções A e B, objetos da pesquisa em Marabá, é na BR 230, os dados indicam similaridade entre $\mathrm{O}$ estudo realizado em Natal e em Marabá.

As análises dos dados indicaram também que, embora tenha ocorrido uma redução significativa da quantidade de veículos nas seções B (25 dB), A (22 dB) e C (2 dB), houve uma tendência de redução no nível de ruído $(2,3$ $\mathrm{dB})$, de B e A em relação a C. A justificativa para o ocorrido é de que, mesmo com a presença da vegetação arbórea e o menor fluxo veicular (2 veículos/minuto), o valor encontrado para a redução do ruído, em C, deveria ser maior, logo, comprovou-se que essa seção recebeu a influência do tráfego das seções A e B. 
Importante destacar que, mesmo com essa influência, o valor de ruído nessa seção foi o menor $(47,9 \mathrm{~dB} ; r=0,72)$ dentre as três seções analisadas, o que significa que os níveis de intensidade sonora aumentavam com o incremento no fluxo de veículos. Mesmo assim, o nível de ruído nessa seção foi o menor dentre as três $(A=50,21 \mathrm{~dB} ; \mathrm{b}=50,23 \mathrm{~dB})$. Esses resultados reafirmaram o que foi visto em Taubaté.

\section{Quanto à arborização presente}

Quanto à arborização presente, os dados obtidos indicaram que, na seção $\mathrm{A}$, há ocorrência da Palmeira Imperial (Roystonea oleracea), no canteiro central; tal vegetal não provocou tendência na diminuição da intensidade do ruído.
Bem como, há vegetação rasteira (Ex.: grama), amenizando o ruído e, o complexo comercial, presente nessa área (oficinas, mecânicas, vendas a varejo e atacado, fluxo de veículos de transporte de matérias pesados, etc.).

No estudo pioneiro efetuado em Estocolmo, por Bolund e Hunhammar (1999), os autores concluiram que, a presença de uma superfície macia ajuda a absorver o ruído, de modo que a associação de plantas rasteiras, como um gramado e um jardim funcionam melhor que o calçamento e árvores no controle do ruído. $\mathrm{Na}$ seção A não há cobertura vegetal, o que acaba corroborando com o estudo pioneiro.

Em relação as seções $\mathrm{B}$ e $\mathrm{C}$, as espécies arbóreas, os dados indicaram uma frequência maior, dentre os indivíduos arbóreos, foi o Oiti (Licania tomentosa) (Tabela 2).

Tabela 2 - Espécies identificadas nas seções B e C da área analisada com as respectivas mensurações de altura total (Ht), diâmetro da copa (DC) e número de indivíduos (NI). Marabá- PA.

Table 2 - Species identified in sections B and C of the analyzed area with the respective measurements of total height (Ht), crown diameter (DC) and number of individuals (NI). Marabá- PA.

\begin{tabular}{ccccc}
\hline Nome popular & Espécie & Ht $(\mathbf{m})$ & DC $(\mathbf{m})$ & NI \\
\hline Ameixa/azeitona & Eugenia jambolana Lam. & 8,58 & 7,60 & 2 \\
Amêndoa & Prunus amygdalos Miller. & 11,64 & 6,08 & 1 \\
Cajú & Anacardium occidentale L. & 2,35 & 1,13 & 1 \\
Figo & Ficus carica L. & 10,37 & 7,97 & 2 \\
Jatobá-curuba & Hymenaea stigonocarpa Mart. ex Hayne & 15,12 & 9,64 & 4 \\
Mamorana & Pachira aquatica Aubl. & 8,26 & 5,82 & 7 \\
Manga & Mangifera indica L. & 12,96 & 7,78 & 2 \\
Maxirimbé & Cenostigma tocantinum Ducke & 6,96 & 6,49 & $1 *$ \\
Mini-Ipê & Tecoma stansi (L.) Juss. ex Kunth & 4,80 & 3,35 & 2 \\
Oiti & Licania tomentosa (Benth.) Fritsch & 10,11 & 7,90 & 30 \\
Pata-de-vaca & Bauhinia variegata L. & 8,58 & 6,03 & 7 \\
Samaúma & Ceiba pentandra (L.) Gaertn. & 16,86 & 10,73 & 2 \\
Tento-da-carolina & Adenanthera pavonina L. & 11,15 & 8,99 & 8 \\
Total & & & 68 \\
\hline
\end{tabular}

Fonte: Autores (2016).

Em A1, os dados indicaram a presença de oito indivíduos, além tento-da-carolina com quatro indivíduos, Jatobá-curuba com três indivíduos arbóreos; A2, quatro indivíduos, além do tentoda-carolina e da Mamorana , com três indivíduos cada espécie; A3 e A4 (nove exemplares em 
cada uma delas), estando a maioria delas as margens da BR 230. Ademais, nas áreas A3 e A4, houve indicação de apenas dois indivíduos por espécie, esses não foram consideradas para essa análise.

A intensidade do ruído apresentou tendência à diminuição quando comparada com as seções A e B (- 2,3 dB), a justificativa é de que ela recebe a influência da barreira sonora, exercida pela vegetação urbana presente na área. Essa diferença indicou que, apesar da presença da barreira arbórea na seção $\mathrm{C}$, essa ainda recebeu influência do ruído proveniente do tráfego das seções A e B, e das atividades (comerciais e religiosas) desenvolvidas próximas a ela.

Pesquisas realizadas em São Paulo - SP, por Amarato-Lourenço et al. (2016), e em Taubaté, por Brito e Monteiro (2015), indicaram que os locais com maior vegetação, em ruas intermediárias, onde seria possível esperar condições mais favoráveis, também apresentaram elevado nível de ruído, influenciado pelo tráfego de veículos (independente da intensidade) das ruas principais, mas tendem a reduzir os incômodos em longo prazo. Em Marabá, os resultados indicaram que há diminuição dos ruídos na seção $\mathrm{C}$, embora o ruído chegue até esse local, advindo das seções A e B, o que corrobora com o relatado nas pesquisas realizadas em São Paulo.

Quanto à relação entre altura total e diâmetro das copas das árvores

Para a análise da tendência de variação do ruído em função da altura Total - Ht (Figura 4), os dados obtidos indicaram uma relação $(\mathrm{r}=$ 0,72), entre essas variáveis, porém, com tendências diferentes quanto aos níveis de ruído: (1) de elevação, nas áreas 1 e 4 (48,62 dB e 48,15 $\mathrm{dB})$, e de (2) diminuição nas áreas 2 e 3 (47,38 $\mathrm{dB}$ e 47, $44 \mathrm{~dB}$ ), quando comparados entre si. Para o diâmetro médio da copa (DC) das árvores, os dados indicaram tendências a quase nulidade entre essas variáveis $(r=0,02)$.

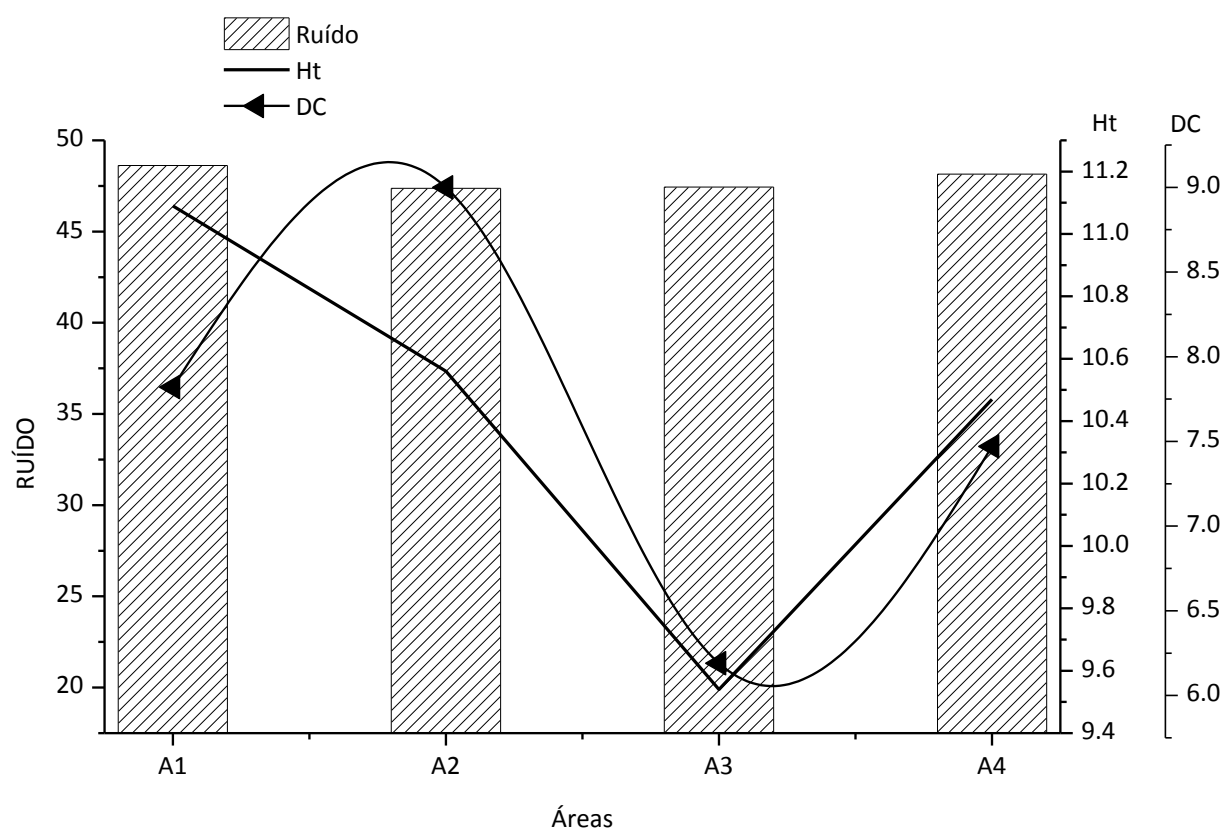

Figura 4 - relação entre os níveis de ruído: A - em relação a altura total (Ht) das árvores; B - em relação ao diâmetro da copa (DC). Seções B e C. Marabá - PA.

Figure 4 - Relation between noise levels: A - in relation to the total height ( $\mathrm{Ht})$ of the trees; B - in relation to the cup diameter (DC). B and C sections. Maraba - PA.

Fonte: Autores (2016). 
Houve indicação também de que a altura da árvore permite a ocorrência da difração do som a partir do tronco (como nas áreas 1 e 4), o inverso também é real, nesse último, o dossel é baixo, tem-se então a barreira sonora, mas, com algumas outras variáveis a serem analisadas (Ex.: tipo de copa; área foliar; densidade da copa, etc.), que não foram objetos dessa pesquisa. Estudo realizado em Istambul, na Turquia, por Avsar e Gonollu, (2005, tradução nossa) os autores concluíram que árvores com altura entre oito e nove metros reduzem o nível de ruído em cerca de 3 a $4 \mathrm{~dB}$.

Outro estudo realizado na Virgínia - EUA, por LEE et al. (2007), concluiu que árvores com até doze metros de altura reduziram para menos de $3 \mathrm{~dB}$ o ruído de tráfego. Em Marabá, a análise dos resultados indicou que a altura total das árvores esteve entre esse intervalo $(8$ - 12) e a redução dos níveis de ruído na $\mathrm{C}$, equivaleu a 2,3 $\mathrm{dB}(\mathrm{A})$, em relação as seções A e B.

Todavia, isso não significa que houve, necessariamente, aumento ou redução do ruído com o aumento ou redução do diâmetro da copa, o que pode ter ocorrido devido as características da copa de cada espécie de árvore $(\mathrm{A} 1, \mathrm{DC}=$ 7,82 m; Nível de Intensidade Sonora - NIS = $48,62 \mathrm{~dB} ; \mathrm{A} 2, \mathrm{DC}=9,00 \mathrm{~m}$; NIS $=47,38 \mathrm{~dB}$; $\mathrm{A} 3, \mathrm{DC}=6,19 \mathrm{~m} ; \mathrm{NIS}=47,44 \mathrm{~dB} ; \mathrm{A} 4, \mathrm{DC}=$ 7,47 m; NIS = 48,15 dB). Importante lembrar que ambas as áreas receberam influência de via arterial em suas extremidades e que na área 4, localiza-se um estacionamento.

$\mathrm{Na}$ pesquisa pioneira realizada em Taipei Taiwan, por Fang e Ling (2003, tradução nossa) os resultados indicaram que cinturões de espécies de árvores com diâmetro da copa médio entre $0,4 \mathrm{~cm}$ e $3,0 \mathrm{~m}$ atenuaram os níveis de ruído em menos de $3 \mathrm{~dB}$. Em Marabá, a média dos valores para diâmetros arbóreos encontrados (6 m a $9 \mathrm{~m}$ ) realizaram uma atenuação do ruído menor que $3 \mathrm{~dB}$.

\section{Conclusões}

A relação entre o fluxo de veículos, em vias arteriais, e a intensidade do ruído ocorre na forma direta, mas o aumento ou diminuição do fluxo de veículos em uma via não implica, necessariamente, em níveis mais elevados ou baixos de intensidade do ruído, pois mesmo em uma via local e com pouco tráfego de veículos, pode haver influência na intensidade do ruído de vias mais movimentadas, como das vias arteriais.

Há também uma relação entre a presença da vegetação, (rasteira ou arbórea), e a interferência na atenuação da intensidade de ruído, a partir da quantidade e da altura total que possuem e, mesmo que o diâmetro da copa seja considerável ou não, contribui para diminuição da intensidade do som, isso em áreas onde a vegetação se faz presente. As espécies arbóreas Licania tomentosa e Pachira aquatica, executam bem a função de barreira acústica e, podem ser utilizadas para o plano de arborização do município, desde que sejam observadas as devidas restrições com relação ao plantio dessas espécies.

\section{Referências Bibliográficas}

ABNT. Associação Brasileira de Normas Técnicas. NBR 10151: Acústica - Avaliação do ruído em áreas habitadas, visando o conforto da comunidade - Procedimento. Rio de Janeiro, 2000 .

AMARATO - LOURENÇO. $F$ et al. Metrópoles, cobertura vegetal, áreas verdes e saúde. Estudos Avançados. São Paulo, v. 30, n. 86, p. s/p., jan./abr., 2016.

AVSAR, Y; GONULLU, M. T. Determination of safe distance between roadway and school buildings to get acceptable school outdoor noise level by using noise barriers. Building and Environment. Istanbul, v. 40, n. 12, p. 12551260, dec, 2005.

AYRES, J. M et al. BioEstat 5.0. 2007. Disponível em: http://www.mamiraua.org.br/ptbr/downloads/programas/. Acesso em: 20 out.2016. 
BERTOLINI, I. C. et al. Avaliação de diferentes métodos para obtenção da área de copa para Araucaria angustifolia (Bertol.) Kuntze. In.: Congresso Florestal Paranaense, 4., 2012, Curitiba. Anais... Curitiba: PR, 2012, p. 1 - 7 .

BOLUND, P.; HUNHAMMAR, S. Ecosystem services in urban areas. Ecological Economic., Stockholm, v. 29, n. 2, p. 293 - 301, may, 1999.

BRITO, L. A. P. F.; MONTEIRO, R. C. R. V. Estudo da influência do Planejamento Urbano na paisagem sonora da região central de Taubaté SP. Revista Brasileira de Gestão e Desenvolvimento Regional. Taubaté, v. 11, n. 3, p. $288-305$, set. /dez, 2015.

BUCHERRI FILHO, A. T.; TONETTI, E. L. Qualidade Ambiental nas paisagens urbanas. Revista Geografar. Curitiba, v.6, n.1, p. 23-54, 2011.

CAETANO, F. D. Classificação de vias urbanas: o Código de Trânsito Brasileiro e os planos diretores municipais no estado do Paraná. 2013. 65 p. Monografia (Especialização em Gerenciamento de obras). Universidade Tecnológica do Paraná, Curitiba: UTFPR, 2013.

FANG, C. F; LING, D. L. Investigation of the noise reduction provided by tree belts. Landscape and Urban Planning. Taiwan, v.63, n.4, p. 187 - 195, 15 may, 2003.

FIGUEIREDO FILHO, D. B; SILVA JÚNIOR, J. A. Desvendando os Mistérios do Coeficiente de Correlação de Pearson ( $r$ ). Revista Política Hoje. Pernambuco, v.18, n.1, p. 115-146, 2009.

KAWAKITA, C. Y. Medição do ruído de tráfego na rodovia $S P 270$ e avaliação da satisfação quanto ao conforto acústico de seus moradores. 2008. 174 f. Dissertação (Mestrado em Engenharia Civil). Escola Politécnica da Universidade de São Paulo, São Paulo, 2008.

LEE, S. E. et al. Road noise attenuation study: Traffic noise, trees, and quiet pavement: A report in response to item 442 c. Of chapter 847 of the Acts of assembly of 2007. Richmond, 2007.

LIMA, A. G. M.; CARVALHO, R. G. Poluição Sonora no meio ambiente urbano - caso centro de Mossoró, Rio Grande do Norte, Brasil. Revista Eletrônica do Prodema, Fortaleza, v. 5, n. 2, p. $69-87$, jun, 2010.

MARABÁ. Plano Municipal de Saneamento Básico - v. I. Tomo I. Marabá, 2013.

MASCARÓ, L.; MASCARÓ, J. L. Vegetação Urbana. 3. ed. Porto Alegre: Masquatro, 2010. $216 \mathrm{p}$.

MURGEL, E. Fundamentos de acústica ambiental. São Paulo: Senac, 2016.136 p.

NICODEMO, M. L. F.; PRIMAVESI, O. Por que manter árvores na área urbana? São Carlos: Embrapa Pecuária Sudeste, 2009 (Documento 89).

PETERNELli, L. A. Curso de Estatística. Capítulo 9 - Regressão linear e correlação, Viçosa: UFV, 2004. Disponível em: <http://www.dpi.ufv.br/ peternelli/inf162.www $.16032004 /$ index.html $>$. Acesso em: 20 out. 2016

PINTO, D. N. et al. Impacto do ruído de tráfego: estudo de caso no bairro de Lagoa Nova, Natal RN. Revista eletrônica de Engenharia Civil. Natal, v.6, n.2, p. 28-37, fev. 2013.

RAIOL. J. A (Coord.) Perspectivas para o meio ambiente urbano. Belém: PNUMA, 2009. 140 p.

RIBEIRO, E. A. W. Cadernos de biogeografia: técnicas de mensuração em espécies arbóreas. v. 1. Presidente Prudente: Azimute, 2011. 23 p.

TYAGI, V.; KUMAR, K.; JAIN, V. K. A study of the spectral characteristics of traffic noise 
attenuation by vegetation belts in Delhi. Applied Acoustics, v. 67, n. 9, p. $926-935,2006$.

ZMITROWICZ, W.; DE ANGELIS NETO, G. Infraestrutura Urbana. São Paulo: EPUSP, 1999. 36 CAETANO, F. D. Classificação de vias urbanas: o Código de Trânsito Brasileiro e os planos diretores municipais no estado do Paraná. 